\title{
Influence of four modern Flettner rotors, used as wind energy capturing system, on container ship stability
}

\author{
Mihail-Vlad Vasilescu ${ }^{1}$, Ionut Voicu ${ }^{2 *}$, Cornel Panait ${ }^{3}$ and Violeta-Vali Ciucur ${ }^{4}$ \\ ${ }^{1}$ Constanta Maritime University, Doctoral School of Mechanical Engineering, 104 Mircea cel Batran \\ street, ZC 900663, Constanta, Romania \\ ${ }^{2}$ Constanta Maritime University, Department of Engineering Sciences in Mechanics and \\ Environment, 104 Mircea cel Batran street, ZC 900663, Constanta, Romania \\ ${ }^{3}$ Constanta Maritime University, Department of General Engineering Sciences, 104 Mircea cel Batran \\ street, ZC 900663, Constanta, Romania \\ ${ }^{4}$ Constanta Maritime University, Department of Electrical Engineering Sciences, 104 Mircea cel \\ Batran street, ZC 900663, Constanta, Romania
}

\begin{abstract}
This article is presenting the influence on the stability of a container ship, by connecting four modern Flettner rotors, as wind energy capturing system. Modern Flettner rotors, are energy power generators. They are one of the various equipment used to capture and harness wind energy. By reading the article, the reader can discover what are the forces which influence the modern Flettner rotors and how they influence the ship stability.This article major points are: calculation the influence of the modern Flettner rotors on the ship transverse and longitudinal stability, calculation of the ship new displacement, new draft, new metacentric height and period of rolling.
\end{abstract}

\section{The benefits of using the Flettner rotors}

Flettner rotors are vertical cylinders that position in the wind front work on the principle of Magnus depending on the wind speed and its direction, propelling the ship [1]. We have installed on a container ship four modern Flettner rotors (Fig.1), with the role of capturing and harnessing wind energy, in order to use it for ship propulsion. These rotors are not the main source of propulsion but contribute to reducing fuel consumption with $3 \%$ to 15 $\%$ depending on vessel size, navigation area and mode of operation. This mode of propulsion is only applicable to those ships that have a free deck, because the wind front captured by the Flettner rotors must not be disturbed. To apply this additional mode of propulsion, the characteristics of the chosen vessel must be carefully analyzed.

By using Flettner rotors, forces appear in the horizontal plane, which, combined with the Magnus effect, modify the stability of the ship, and can also be a danger of shearing the rotor support poles.

${ }^{*}$ Corresponding author: panaitescumariana1@gmail.com 
The results of wind propulsion suggest that when this technology is implemented at scale, it can produce up to $20 \%$ net savings in fuel costs with a payback period of less than four years at current fuel prices, confirming that wind technologies are commercially-viable solutions that reduce fuel and carbon emissions in the industry [3]. When the speed of wind are favourable, this solution allow the main engines to be throttled back, saving fuel and reducing emissions while providing the power needed to maintain speed and voyage time. The Flettner rotors can be used with new vessels or with existing ships without off-hire costs. The existing installation on the ship can be completed with the Flettner rotor support foundation when desired and there is a stationary quay. There are many reccommended solutions by the international companies (e.g. Norsepower and Bore Ltd of Finland).

This case study is an example of the use of renewable energy resources with an impact on the environment and climate change that we analyzed during the HORESEC project PN-III-P1-1.2-PCCDI-2017-0404 /31PCCDI/2018, Holistic on the Impact of Renewable Energy Sources on Environment and Climate.

\subsection{Principle characteristics of the ship and modern Flettner rotors}

For the study of propulsion with Flettner rotors, a container was chosen as the study vessel, having the following technical characteristics ( Fig. 1) [2]:

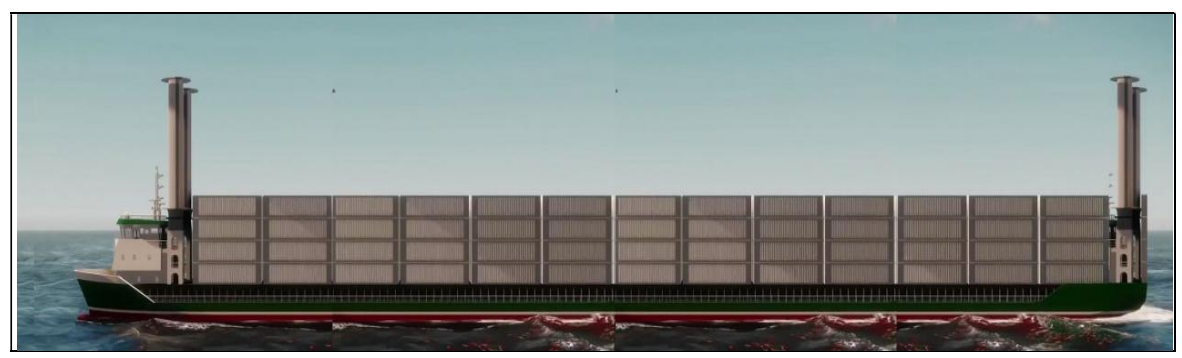

Fig. 1. Container ship with four modern Flettner rotors installed on deck

- $\quad$ Ship displacement: $39449 \mathrm{mt}$

- $\quad$ Ship width: $29.4 \mathrm{~m}$

- $\quad$ Ship length: $168.56 \mathrm{~m}$

- Height of the rotor: $24 \mathrm{~m}$

- Diameter of the rotor: $4 \mathrm{~m}$

- Weight of the rotor: $40 \mathrm{~kg}$.

\section{Calculation of the new displacement $D^{\text {' }}$}

where:

$$
D^{`}=D+4 \times m=39449+160=39609 m t
$$

" $\mathrm{m}$ " is the mass of one modern Flettner rotor.

\section{Calculation of the ship draft at the new displacement $D$ '}

The new displacement is $\mathrm{D}^{`}=39609 \mathrm{mt}$. 
By interpolation from hydrostatic tables we extracted for any draft the mass which must be loaded or discharged to change a ship's mean draft by one centimeter [1]. We will note this size with TPC.

The TPC for any draft isTPC $=45.47$. The difference between displacements is:

$$
D^{`}-D_{9,59}=23.96 m t
$$

For new draft

$$
T^{\prime} P=9.59+\left(D^{`}-D_{9,59} / T P C\right) \times 0.01=9.5952 \mathrm{~m} .
$$

\section{Calculation of the ship longitudinal stability}

A surface ship's stability can be divided into two parts [4]: intact stability and damaged stability. The intact stability is when the intactness of its hull is maintained. The damaged stability means that the some compartments or tanks are flooded by seawater [5].

\subsection{Determination of KG}

The vertical distance between the keel and the center of gravity is expressed as ' $\mathrm{KG}$ ' [4]. We note with

- "GM" the metacentric height; it is a measurement of the initial static stability of a floating body; it represent the distance between the centre of gravity $\mathrm{G}$ of a ship and its metacentre $\mathrm{M}$ (Fig. 2)[4];

- "TKM" the transverse stability; it is the distance between the keel $\mathrm{K}$ and the tranverse metacenter M;

- "KM"the distance from keel to the metacentre.

The ship stability condition are preseted in the Figure 2 and the ship stability conditions with the four modern Flettner rotor are presented in the Figure 3.

$$
G M=K M_{T}-K G
$$

Fig. 2. Ship stability initial condition
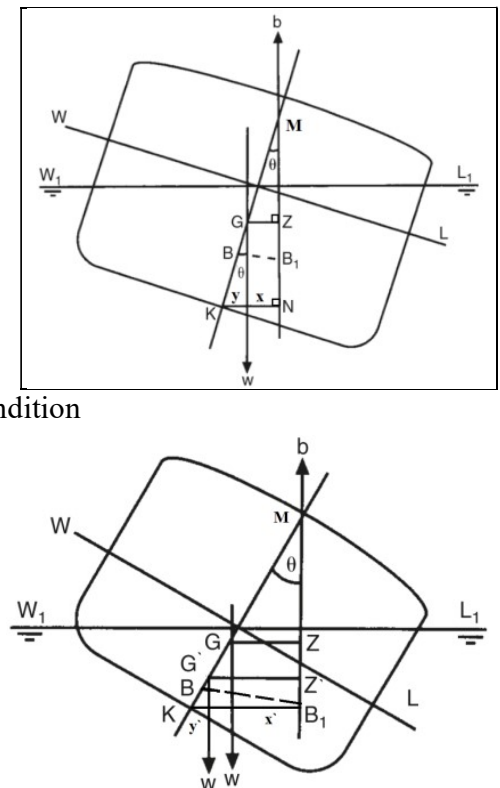

Fig. 3. Ship stability condition after the installation on the deck of the four modern Flettner rotors 
So, for our case study: $\mathrm{GM}=4.32 \mathrm{~m} ; \mathrm{TKM}=\mathrm{KM}_{\mathrm{T}}=12.32 \mathrm{~m}$. According to equation (4) this means $\mathrm{KG}=8 \mathrm{~m}$.

\subsection{Determination of the transverse stability and longitudinal stability for the new draft}

For transverse metacentre $\mathrm{T}_{\mathrm{P}}=9.5952 \mathrm{~m}$, by interpolation from hydrostatic tables we extracted for the new draft the transverse stabilityTKM ' and longitudinal stability LKM'.

$\mathrm{TKM}^{`}=\mathrm{KM}_{\mathrm{T}}{ }^{\prime}=12.3548 \mathrm{~m}$;

$\mathrm{LKM}^{\prime}=\mathrm{KM}_{\mathrm{L}}{ }^{\prime}=231.7072 \mathrm{~m}$, where:

Transverse metacentre- the point of intersection of the vertical through the center of buoyancy of a ship in the position of equilibrium with the vertical through the new center of buoyancy when the ship is slightly heeled.

Longitudinal metacentre - the point in a vertical line through the centre of gravity of a ship where this line is intersected by a second vertical line through the centre of buoyancy when the ship is inclined at a very small angle in a fore and aft direction.

LKM- longitudinal stability is the distance between the keel $\mathrm{K}$ and the longitudinal metacenter $\mathrm{M}$.

\subsection{Determination of new metacentric height GM'}

We note with:

- "ML" the longitudinal metacentre meaning the metacentre of the ship in its longitudinal direction;

- "GML" the longitudinal metacentric height of the ship;

- "KM" the distance from keel $\mathrm{K}$ to the metacentre $\mathrm{M}$;

- "KG" the distance from keel $\mathrm{K}$ to the centre of gravity $\mathrm{G}$;

- "G'M" the new metacentric height;

For our case study, with $\mathrm{KG}=8$ we obtain the the value of new metacentric height:

$$
G^{\prime} M=K M_{T}-K G=4.3548 m
$$

\subsection{Determination of the ship initial righting lever $G Z$, in order to calculate the ship transverse stability}

$$
\begin{aligned}
& K N=x+y ; \\
& x=G Z ; \\
& y=K G x \sin \theta ; \\
& K N=G Z+K G x \sin \theta \\
& G Z=K N-K G \times \sin \theta
\end{aligned}
$$

where

$\theta$ - the angle of heel (Fig. 2; Fig. 3); GZ- the righting lever; B- the centre of buoyancy; WLthe water line; w- the weight; KG- the vertical distance between the keel and the center of gravity [5].

For our case study:

$\mathrm{GM}=4.3200 \mathrm{~m} ; \mathrm{D}=39449 \mathrm{mt}$. The variation of $\mathrm{GZ}$ for different values of the angle of heel is presented in the Table 1: 
Table 1. GZ calculated for different values of the $\theta$ angle from $0^{\circ}$ to $90^{\circ}$ :

\begin{tabular}{|c|c|c|c|c|c|}
\hline$\theta$ & $\operatorname{Sin} \theta$ & KG & KN & KG x $\sin \theta$ & GZ \\
\hline 0 & 0.000 & 8 & 0.000 & 0.000 & 0.000 \\
\hline 10 & 0.174 & 8 & 2.113 & 1.392 & 0.721 \\
\hline 20 & 0.342 & 8 & 4.260 & 2.736 & 1.524 \\
\hline 30 & 0.500 & 8 & 6.310 & 4.000 & 2.310 \\
\hline 40 & 0.640 & 8 & 7.830 & 5.120 & 2.710 \\
\hline 45 & 0.707 & 8 & 8.396 & 5.656 & 2.740 \\
\hline 50 & 0.766 & 8 & 8.828 & 6.128 & 2.700 \\
\hline 60 & 0.866 & 8 & 9.330 & 6.928 & 2.402 \\
\hline 70 & 0.939 & 8 & 9.332 & 7.512 & 1.820 \\
\hline 80 & 0.984 & 8 & 8.892 & 7.872 & 1.020 \\
\hline 90 & 1.000 & 8 & 8.010 & 8.000 & 0.010 \\
\hline
\end{tabular}

\subsection{Determination of the new righting lever $G^{\prime} Z^{\prime}$, in order to determine the ship transverse stability}

$$
\begin{aligned}
& K N=x{ }^{`}+y^{`} \\
& x^{`}=G^{`} Z^{`} \\
& y^{`}=K G^{`} x \sin \theta \\
& K N=G^{`} Z^{\prime}+K G^{`} x \sin \theta \\
& G^{`} Z^{`}=K N-K G^{`} x \sin \theta
\end{aligned}
$$

For our case study : $\mathrm{GM}^{`}=4.3548 \mathrm{~m} ; \mathrm{D}^{`}=39609 \mathrm{mt}$, where

$\theta$ - the angle of heel; $G^{\prime} Z^{\prime}$ - the new righting lever; $B$ - the centre of buoyancy [5]; $\mathrm{KG}^{\prime}$ distance from keel $\mathrm{K}$ to the centre of gravity $\mathrm{G} ; \mathrm{G}^{\prime} Z^{\prime}$ - the new righting lever after the centre of gravity moved; $G^{\prime} M$ - the new metacentre height, it is a measurement of the initial static stability of a floating body. It is the distance between the centre of gravity $G^{\prime}$ of a ship and its metacentre M; WL- water line; w- weight; KM- distance from keel to the metacentre.

Table 2. G $Z^{`}$ calculated for different values of the $\theta$ angle from 0 to $90^{\circ}$

\begin{tabular}{|c|c|c|c|c|c|}
\hline$\theta$ & $\operatorname{Sin} \theta$ & KG $^{\prime}$ & KN $^{`}$ & KG $^{\prime} \times \sin \theta$ & $\mathrm{G}^{\prime} Z^{\prime}$ \\
\hline 0 & 0.000 & 8.0348 & 0.000 & 0.000 & 0.000 \\
\hline 10 & 0.174 & 8.0348 & 2.127 & 1.398 & 0.729 \\
\hline 20 & 0.342 & 8.0348 & 4.280 & 2.749 & 1.531 \\
\hline 30 & 0.500 & 8.0348 & 6.337 & 4.017 & 2.320 \\
\hline 40 & 0.640 & 8.0348 & 7.853 & 5.142 & 2.711 \\
\hline 45 & 0.707 & 8.0348 & 8.423 & 5.680 & 2.743 \\
\hline 50 & 0.766 & 8.0348 & 8.866 & 6.154 & 2.712 \\
\hline 60 & 0.866 & 8.0348 & 9.368 & 6.958 & 2.410 \\
\hline 70 & 0.939 & 8.0348 & 9.365 & 7.544 & 1.821 \\
\hline 80 & 0.984 & 8.0348 & 8.931 & 7.9060 & 1.025 \\
\hline 90 & 1.000 & 8.0348 & 8.045 & 8.034 & 0.011 \\
\hline
\end{tabular}

The transverse stability curve is plotted on the graph with black (Fig. 4). 
$G$
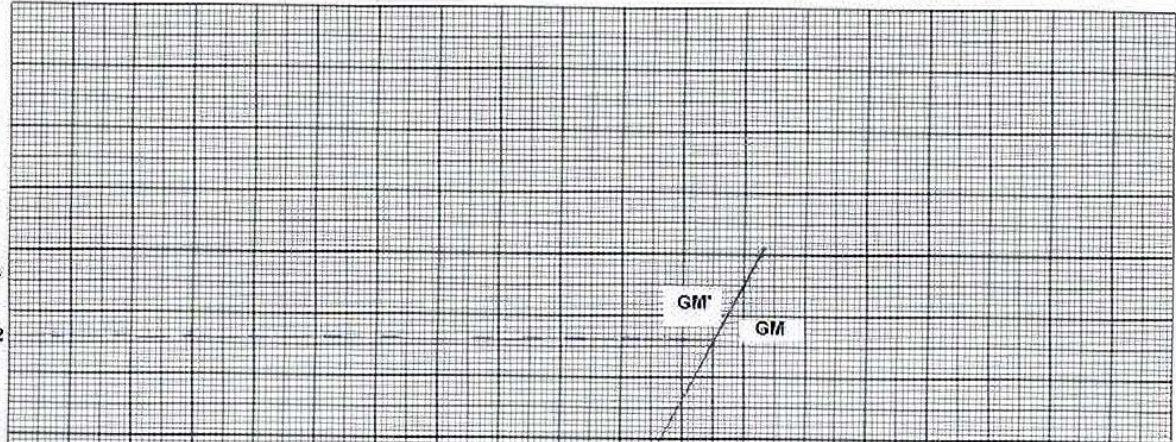

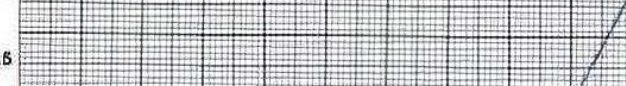

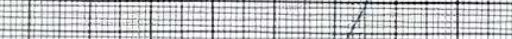

3

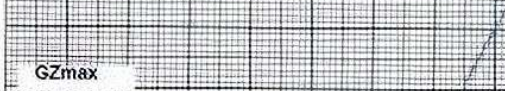

$\operatorname{GZmax}+\ldots$

2.4

G'Zmax

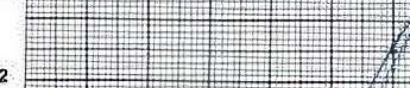

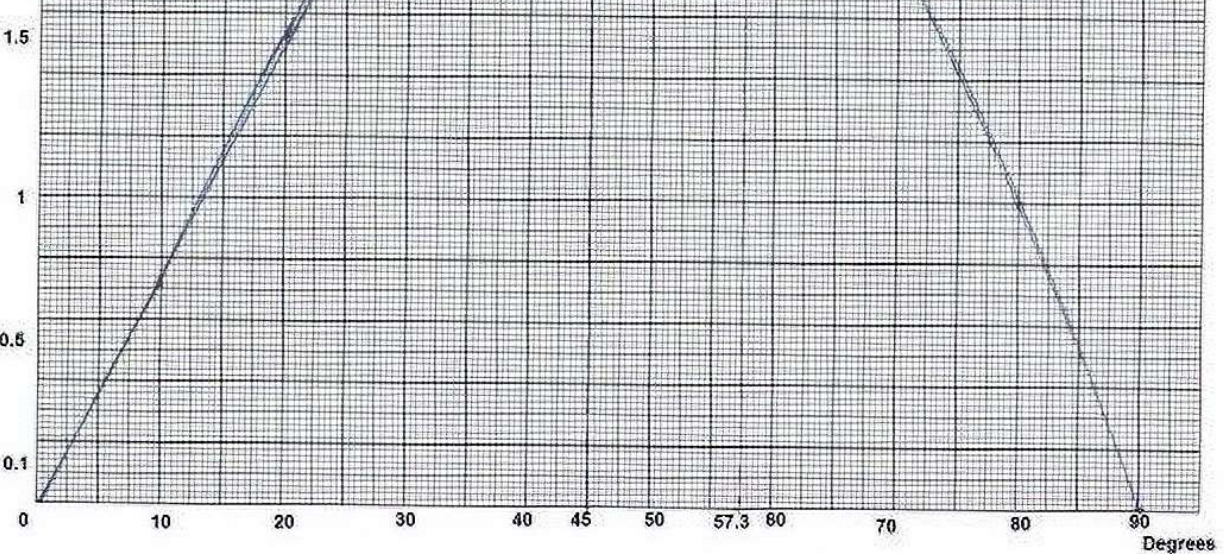

Fig. 4. Transverse stability graph

The graph represents the curve of the static stability of the ship and the variation of the stability righting lever according to the variation of the transverse tilt angle of the ship. The 
initial stability is presented without the energy generating equipment. The final stability is presented with the energy generating equipment installed.

\section{The interpretation of graph is:}

$>$ Point $\mathrm{O}$, represents the origin of the curve;

$>$ Point $\mathrm{M}$ and $\mathrm{M}$, maximum point of the curve, critical angle of roll or maximum angle of canary; the point where the recovery arm has the maximum value;

$>$ Point $\mathrm{V}$, represents the point of sunset or decline;

$>$ Increasing branch, is between $\mathrm{O}$ and $\mathrm{M}$ respectively $\mathrm{O}$ and $\mathrm{M}$;

$>\varphi_{v}$ the maximum inclination angle, at which the vessel, left free, returns to its initial equilibrium position;

$>\varphi_{\mathrm{m}}$, is the angle of inclination at which the openings in the body of the ship, superstructures which cannot be sealed, are flooded;

$>$ The area delimited by the static stability curve and by the abscissa represents the total mechanical work of the recovery moment, meaning the mechanical work with which the ship is able to withstand the external moments applied dynamical; this area represents the dynamic stability reserve of the ship;

Flood angle of the deck is identified on the static stability curve as the point at which the curve changes its shape from rising to decreasing on the rising branch.

$>$ It is also known as the turning point of the curve. This point can be determined by drawing series of vertical lines on the stability curve.

$>$ Analyzing each delimited area can determine the point at which the curve changes its tendency from ascending to descending. It is a difficult problem to approximate and always leaves room for interpretation.

For

$$
G^{\prime} M>G M ;
$$

ship transverse stability has been increased, after the placement of the four modern Flettner rotors, comparing with initial stability [6].

\subsection{Determination of the rolling period}

The rolling period can be calculated on formula [7]

$$
T=2 x l x C x 1 / G M^{1 / 2}
$$

Where:

1- ship width; $1=29.4 \mathrm{~m}$; C-the coefficient describing ships transverse gyration radius; $\mathrm{C}=$ 0.371 [7] for $\mathrm{T}_{\mathrm{p}}{ }^{\prime}=9.5952 \mathrm{~m} ; \mathrm{GM}=4.3200 \mathrm{~m} ; \mathrm{G}^{\prime} \mathrm{M}=4.3548 \mathrm{~m}$; $\mathrm{T}$ - initial rolling period; $\mathrm{T}$ $=10.4956 \mathrm{~s}$; $\mathrm{T}^{\prime}-$ the rolling period after the placement of the four modern Flettner rotors that generates green, unconventional energy; $\mathrm{T}^{\prime}=10.4536 \mathrm{~s}$.

From the graph we can also observe that the ship has an initial faster rolling period comparing with the rolling period after the placement of the four modern Flettner rotors, which is slower [2].

$$
T>T^{v} \quad 10.4956>10.4536 .
$$




\subsection{Determination of the inclining moments of the ship}

\subsubsection{Stable wind}

$$
\begin{aligned}
& l_{w l}=0,0514 \times A x Z \times 1 / D \\
& l_{w l}=0,0514 x A^{\prime} \times Z^{\prime} \times 1 / D^{\prime}
\end{aligned}
$$

where:

D - initial ship displacement; D' - displacement of the ship, after the connection of the balloon with the ship; A- the wind pressure area on the hull of the ship and on the cargo on the deck above the waterline, calculated for a draft $T_{p}=9.56 \mathrm{~m}$ and a D $=39449 \mathrm{mt}$; $\mathrm{A}^{\prime}-$ the wind pressure area on the hull of the ship and on the cargo on the deck above the waterline, calculated for a draft $T_{\mathrm{p}}{ }^{\prime}=9.5952 \mathrm{~m}$ and a $\mathrm{D}^{`}=39609 \mathrm{mt} ; \mathrm{Z}$ - vertical distance between the center of $A$ and the center of the lateral area of the keel,at a draft of $T_{p}=9.56 \mathrm{~m}$ and a D $=$ $39449 \mathrm{mt}$; $Z$ - vertical distance between and the center of the lateral area of the keel, at a draft of $\mathrm{T}_{\mathrm{p}}{ }^{`}=9.5952 \mathrm{~m}$ and $\mathrm{D}^{`}=39609 \mathrm{mt} ; \mathrm{T}_{\mathrm{p}}=9.56 \mathrm{~m} ; \mathrm{D}=39449 \mathrm{mt}$.

\section{Calculation of $A$}

By interpolation from wind area table (Beaufort Scale), for a draft $\mathrm{T}_{\mathrm{p}}=9.56 \mathrm{~m}$, results $\mathrm{A}=$ $1478.9936 \mathrm{~m}^{2} \sim 1479 \mathrm{~m}^{2}$.

\section{Calculation of $Z$}

By interpolation from wind area table, for a draft $T_{p}=9.56 \mathrm{~m}$ results $Z=10.2272 \mathrm{~m} \sim$ $10.23 \mathrm{~m}$.

$1_{\mathrm{w} 1}=0.019708 ; \mathrm{Tp}{ }^{`}=9.5952 \mathrm{~m} ; \mathrm{D}^{`}=39609 \mathrm{mt}$.

\section{Calculation of $A$}

By interpolation from wind area table, for a draft $T_{P}{ }^{`}=9.5952 m$, results $A{ }^{`}=1472.9589 \mathrm{~m}^{2} \sim$ $1473 \mathrm{~m}$.

\section{Calculation of $Z$}

By interpolation from wind area table, for a draft $T_{\mathrm{P}}{ }^{`}=9.5952 \mathrm{~m}$, results $Z=10.231424$ $\sim 10.231 \mathrm{~m}$ $1_{\mathrm{w} 1}=0.0195567172 \mathrm{~m} \sim 0.0196 \mathrm{~m}$.

\subsubsection{In case of a gust of wind}

$$
\begin{aligned}
& l_{w 2}=1.5 l_{w 1} \\
& l_{w 2}=1.5 l_{w 1}
\end{aligned}
$$

$\mathrm{T}_{\mathrm{P}}=9.56 \mathrm{~m} ; \mathrm{D}=39449 \mathrm{mt} ; 1_{\mathrm{w} 2}=0.029562 \mathrm{~m} \sim 0.296 \mathrm{~m} ; T_{P}{ }^{`}=9.5952 \mathrm{~m} ; \mathrm{D}{ }^{`}=39609 \mathrm{mt} ;$ $1_{\mathrm{w} 2}=0.0293350758 \mathrm{~m} \sim 0.0293 \mathrm{~m}$.

\section{Calculation of the ship longitudinal stability and its effect on the ship trim}

The moment of change trim one centimeter is given by equation (21) 
where:

$$
M T C^{l} \mathrm{~cm}=D x G M L x 1 / 100 L
$$

MTC- the moment of change trim one centimeter; D- ship displacement; L- ship length; GML- GM longitudinal.

\subsection{Calculation of the MTC ${ }^{\prime}$ for $T_{{ }_{P}}=9,5952 \mathrm{~m}$}

By interpolation in hydrostatic tables at $\mathrm{T}_{\mathrm{P}^{\prime}}$, results $\mathrm{MTC}^{\prime}=532,8804 \mathrm{mt} \mathrm{x} \mathrm{m}$; MTC - final MTC after the installation of four modern Flettner rotors on the ship main deck; MTC = $531.92 \times \mathrm{m}$.

We can observe that:

$$
M T C<M T C^{\backslash} \quad 531.9200<532.8804 .
$$

\subsection{Calculation of initial GML}

$$
M T C^{l} \mathrm{~cm}=D x G M L x 1 / 100 L
$$

$\mathrm{L}=168.56 \mathrm{~m} ; \mathrm{D}=39449 \mathrm{mt}$;

$$
G M_{L}=M T C x 100 x L x 1 / D^{=} 227.281 \mathrm{~m}
$$

\subsection{Calculation of G'ML}

$$
M T C^{l} \mathrm{~cm}=\operatorname{DxGML} \times 1 / D^{\prime}
$$

$\mathrm{D} `=39609 \mathrm{mt} ;$

$$
G M L^{\prime}=M T C^{\prime} \times 100 x L x 1 / D^{\prime}=226.773 \mathrm{~m} .
$$

Because GML >GML', $227.281>226.7725$ it means that the longitudinal stability of the ship, after the positioning the four modern Flettner rotors, has reduced.

\section{Conclusions}

From this paper we can see that the four modern Flettner rotors, positioned on the ship are not influencing to much the ship stability.

From the stability point of view, transverse stability has improved:

but the value is insignificant.

$$
G^{\prime} M>G M \quad 4.3548>4.3200
$$

Longitudinal stability of the ship, after the four modern Flettner rotors, were positioned on the ship, was reduced:

$$
G M L>G^{\prime} M L \quad 227.281>226.7725
$$

After positioning the four modern Flettner rotors on the container ship, we can observe that the rolling period has decreased:

$$
T>T \quad 10.4956>10.4536
$$


We consider that the installation of four modern Flettner rotors on a container ship, it is possible, beneficial in terms of reducing fossil fuel consumption, reducing greenhouse gas emissions, saving money for the owners and is safe for navigation.

This paper has financial support from the Constanta Maritime University under assistance project PN-III-P1-1.2-PCCDI-2017-0404/31PCCDI/2018, Holistic on the Impact of Renewable Energy Sources on Environment and Climate-HORESEC.

\section{References}

[1] GlopMEEP, Technology. Flettner rotors, Global maritime energy efficiency partnerships, Information portal J. 4 (2018)

[2] M.V. Vasilescu, M. Panaitescu, F.V. Panaitescu, C. Panait, Efficiency of using a hybrid marine propulsion system vs. conventional system, SPIE Proc. Advanced Topics in Optoelectronics, Microelectronics and Nanotechnologie (to be published)

[3] J. Frith, Wind rotors for ships, Maritime J. 612 (2015)

[4] M. Rhodes, Ship Stability for Mates/Masters, Seamanship International Ltd, Glasgow, 21 (2003).

[5] S. Chakraborty, Ship Stability - Understanding Intact Stability of Ships, Naval architecture J. 27 (2019)

[6] B. Barras, D. Derrett, Ship Stability (Masters and Mates), sixth edition, Elsevier, London, 44 (2006).

[7] W. Wawrzyński, P. Krata, Method for ship's rolling period prediction with regard to non-linearity of GZ curve, Journal of Theoretical and Applied Mechanics 54(4) 1329-1343, (2016), DOI: https://doi.org/10.15632/jtam-pl.54.4.1329

[8] M.V. Vasilescu, M. Panaitescu, F.V. Panaitescu, C. Panait, Choose the best electricity sources for a container ship, by using a hybrid optimization model for electric renewable, SPIE Proc. Advanced Topics in Optoelectronics, Microelectronics and Nanotechnologie (to be published)

[9] A. Maruccia, Optimisation model for a ship's hybrid energy system with a Flettner rotor, Master thesys, 1 81(2019). 